\title{
Estresse ocupacional e engajamento no trabalho entre policiais militares
}

\author{
Occupational stress and work engagement \\ among military police officers
}

Fernando Braga dos Santos (http://orcid.org/0000-0002-7775-2521) ${ }^{1}$

Luciano Garcia Lourenção (http://orcid.org/0000-0002-1240-4702) ${ }^{1}$

Evellym Vieira (https://orcid.org/0000-0003-1818-6846) ${ }^{1}$

Francisco Rosemiro Guimarães Ximenes Neto (https://orcid.org/0000-0002-7905-9990) ${ }^{2}$

Adriane Maria Netto de Oliveira (https://orcid.org/0000-0001-9422-423X) ${ }^{1}$

Jacqueline Flores de Oliveira (https://orcid.org/0000-0002-0598-3881) ${ }^{1}$

Márcio Andrade Borges (https://orcid.org/0000-0002-4597-2597) ${ }^{1}$

Thiago Roberto Arroyo (https://orcid.org/0000-0002-3759-4346) ${ }^{3}$

${ }^{1}$ Escola de Enfermagem, Universidade Federal do Rio Grande. Rio Grande, Rio Grande do Sul, Brasil. Rua General Osório s/no $4^{\circ}$ piso sala 10, Centro. 96201900 Rio Grande RS Brasil. lucianolourencao.enf@ gmail.com

${ }^{2}$ Centro de Ciências da

Saúde, Universidade Estadual Vale do Acaraú UVA. Sobral Ceará Brasil. ${ }^{3}$ Faculdade de Medicina de São José do Rio Preto. São José do Rio Preto São Paulo Brasil.

\begin{abstract}
This paper investigates the levels of occupational stress and work engagement among military police officers. This cross-sectional, descriptive, and analytical study was conducted with 268 police officers from the $3^{\text {rd }}$ Military Police Battalion of Parana state. We observed significant levels of occupational stress in 125 (46.7\%) police officers. The main stressors were lack of career growth prospects $(3.7 ; \pm 1.3)$; inadequate training $(3.4 ; \pm 1.2)$; discrimination/favoritism in the work environment $(3.1 ; \pm 1.4)$; long working hours (3.0; $\pm 1.4)$; distribution of tasks $(2.7 ; \pm 1.1)$; control type $(2.7 ; \pm 1.1)$; gaps in disclosing information about organizational decisions $(2.7 ; \pm 1.2)$; low valuation $(2.7 ; \pm 1.2)$. Levels of work engagement ranged from 3.8 [medium] to 4.1 [high]. The correlation between occupational stress and work engagement was low for the dimensions of Absorption ( $r$ : $-.284 ; p<0.001)$ and Overall Score $(r:-0.393 ; p<0.001)$ and moderate for the dimensions Vigor ( $r$ : $-0.422 ; p<0.001)$ and Dedication ( $r:-0.414 ; p<0.001)$. We concluded that an important number of police officers had shown occupational stress. However, they displayed good levels of work engagement and are enthusiastic, inspired, and proud of their work.
\end{abstract}

Key word Occupational stress, Work engagement, Police, Military personnel
Resumo Este artigo investiga os níveis de estresse ocupacional e engajamento no trabalho entre policiais militares. Estudo transversal, descritivo e analítico, com 268 policiais do $3^{\circ}$ Batalhão de Polícia Militar do estado do Paraná. Observou-se níveis importantes de estresse ocupacional em 125 (46,7\%) policiais. Os principais estressores foram: falta de perspectivas de crescimento na carreira $(3,7 ; \pm 1,3)$; deficiência nos treinamentos $(3,4$; $\pm 1,2)$; presença de discriminação/favoritismo no ambiente de trabalho $(3,1 ; \pm 1,4)$; longas jornadas de trabalho $(3,0 ; \pm 1,4)$; forma de distribuição das tarefas $(2,7 ; \pm 1,1)$; tipo de controle $(2,7 ; \pm 1,1)$; deficiência na divulgação de informações sobre decisões organizacionais $(2,7 ; \pm 1,2)$; baixa valorização $(2,7 ; \pm 1,2)$. Os níveis de engajamento no trabalho variaram de 3,8 [médio] a 4,1 [alto]. A correlação entre estresse ocupacional e engajamento no trabalho foi baixa para as dimensões 'Absorção' (r: -0,284; $p<0,001)$ e 'Escore geral' ( $r$ : -0,393; $p<0,001)$ e moderada para as dimensões 'Vigor' (r: -0,422; $p<0,001)$ e 'Dedicação' ( $r$ : -0,414; $p<0,001)$. Concluiu-se que há um importante número de policiais com estresse ocupacional que, no entanto, apresentam bons niveis de engajamento no trabalho e mostram-se entusiasmados, inspirados e orgulhosos com o seu trabalho.

Palavras-chave Estresse Ocupacional, Engajamento no trabalho, Policia, Militares 


\section{Introdução}

O fornecimento de um serviço de segurança apropriado à população é aspecto crucial na execução do trabalho da polícia, sobretudo por conta do avanço da criminalidade e violência, em âmbito social e comunitário, que se institucionaliza e se aperfeiçoa na sociedade contemporânea brasileira. No entanto, as atividades laborais dos policiais militares são amplamente associadas ao adoecimento e comprometimento da sua capacidade de trabalho. Logo, a saúde física e psicológica destes possuem estrita relação com o exercício da atividade laborativa, tornando-se problema relevante para a saúde do trabalhador na atualidade ${ }^{1-4}$.

A demanda de respostas do serviço de segurança prestado à sociedade tem impactos organizacionais e políticos, visto que o ambiente e o processo de trabalho dos policiais militares trazem implicações importantes para a saúde, o bem-estar e a produtividade destes profissionais, refletindo diretamente na qualidade e resolutividade do serviço de segurança. Nesse contexto, a violação do direito dos policiais a condições dignas de trabalho representa uma forma de violência no ambiente laboral, que pode prejudicar o comprometimento e o desempenho profissional destes trabalhadores ${ }^{1-3,5}$.

Quando satisfeitos e realizados profissionalmente, os policiais apoiam mais os colegas de trabalho e aos superiores, que pode resultar em níveis ainda mais altos de bem-estar e motivação. Esse sentimento de satisfação com o trabalho compreende o engajamento no trabalho, um estado cognitivo afetivo positivo, relacionado à profissão, que envolve comprometimento e alinhamento do profissional com o ambiente e a atividade laboral ${ }^{6-8}$.

De acordo com a literatura, os recursos de trabalho, como oportunidades de aprendizado, boa ambiência e apoio, exercem um papel fundamental no bem-estar motivacional dos trabalhadores, satisfazendo suas necessidades psicológicas de competência e autonomia. Contudo, se profissionais satisfeitos e envolvidos com o trabalho tendem a encarar a atividade laboral como desafiadora e divertida, com energia, disposição e motivação, quando frustrados psicologicamente, estes podem apresentar esgotamento, desânimo e falta de motivação, que geram perda de recursos energéticos e afetam a produção laboral, culminando com o desenvolvimento de patologias associadas ao esgotamento mental ${ }^{6}$.

Nesse caso, o desgaste do trabalhador advindo do desequilíbrio em sua relação com o am- biente laboral é classificado como estresse ocupacional. Entre as causas do estresse ocupacional destaca-se a sobrecarga qualitativa e quantitativa de funções, que tornam o ambiente laboral ameaçador, comprometendo a produtividade do trabalhador e impedindo-o de realizar-se pessoal e profissionalmente?.

No estado de São Paulo, estudo com 506 policiais militares evidenciou que, embora os profissionais afirmem estar satisfeitos com a saúde, sofrem comprometimento da qualidade de vida em aspectos relacionados ao ambiente. Os dados auxiliam no entendimento de que existe uma associação significante entre elevados níveis de estresse e má qualidade de vida, revelando a necessidade de políticas que promovam mecanismos de enfrentamento, para melhorar a qualidade de vida deste público, refletindo diretamente no serviço de segurança pública ${ }^{10}$.

Portanto, diante da relevância do trabalho do policial militar para a sociedade, é notória a importância de se identificar fatores de estresse ocupacional relacionados ao processo de trabalho e sua implicação com a saúde, o bem-estar e a satisfação laboral destes profissionais. Ante o exposto, este estudo objetiva investigar os níveis de estresse ocupacional e engajamento no trabalho em policiais militares.

\section{Métodos}

Estudo transversal, descritivo e analítico, realizado com policiais do $3^{\circ}$ Batalhão de Polícia Militar do Paraná (3 BPM/PR), no ano de 2018.

$\mathrm{O} 3^{\circ} \mathrm{BPM} / \mathrm{PR}$ pertence ao $5^{\circ}$ Comando Regional de Polícia Militar do Estado e atende uma população de aproximadamente 260 mil habitantes, distribuída em 16 municípios da microrregião do sudoeste do Paraná ${ }^{11}$.

Sediado na Cidade de Pato Branco, o $3^{\circ}$ BPM/ PR conta com 312 policiais, que realizam o policiamento nas áreas urbana e rural, fiscalização de trânsito, condução de cães farejadores, presença em shows e eventos, e contam com uma estrutura para intervenção em distúrbios civis e rebeliões ${ }^{11}$.

A população do estudo foi constituída pelos policiais militares integrantes do $3^{\circ} \mathrm{BPM} / \mathrm{PR}$ que, depois de convidados, aceitaram participar do estudo. Foram excluídos os profissionais que estavam de férias ou afastados das atividades laborais, por problemas de saúde, licença ou qualquer outro motivo, no período da coleta dos dados.

Para a coleta dos dados foram utilizados três instrumentos, sendo um com informações sobre 
o perfil sociodemográfico e profissional dos policiais (sexo, faixa etária, estado civil, escolaridade, cargo, tempo de serviço, jornada de trabalho, turno de trabalho, prática de atividade física e se respondeu por transgressões disciplinares); a Escala de Estresse no Trabalho (EET), validada por Paschoal e Tamayo ${ }^{12} \mathrm{e}$ a versão brasileira da Utrecht Work Engagement Scale (UWES), validada por Vazquez e colaboradores ${ }^{13}$.

A EET é composta por dados sociodemográficos e 23 afirmativas negativas, com uma escala de cinco pontos, variando desde "discordo totalmente" a "concordo totalmente". Seus indicadores foram elaborados a partir da análise da literatura sobre estressores organizacionais de natureza psicossocial e sobre reações psicológicas ao estresse ocupacional. A escala possui características psicométricas satisfatórias e pode contribuir, tanto para pesquisas sobre o tema, quanto para o diagnóstico do ambiente organizacional. É uma ferramenta para diagnóstico organizacional que foi submetida a testes e requisitos psicométricos $^{12}$.

A UWES é composta por 17 itens que avaliam o nível de satisfação do indivíduo com o trabalho. A escala avalia os três aspectos constituintes do engajamento no trabalho (dedicação, absorção e vigor) e foi validada em diversos países ${ }^{13}$.

Os dados obtidos foram armazenados em um banco de dados utilizando-se uma planilha do programa Microsoft Excel ${ }^{\circledR}$ e analisados com o programa Statistical Package for Social Sciences (SPSS), versão 23.0. As variáveis sociodemográficas e profissionais foram utilizadas para descrever o perfil dos policiais militares.

O estresse ocupacional foi avaliado a partir do cálculo de um escore médio obtido pelos policiais, identificando os estressores mais presentes, segundo a percepção dos policiais. Em seguida, realizou-se análise descritiva das variáveis sociodemográficas e profissionais, segundo a presença ou não de estresse ocupacional.

Os indicadores da EET variam de um a cinco e, quanto maior a média, maior o estresse. Consideram-se indicadores de níveis importantes de estresse os valores médios iguais ou superiores a 2,5 .

Os cálculos dos escores das dimensões do engajamento no trabalho foram realizados conforme modelo estatístico proposto no Manual Preliminar UWES - Utrecht Work Engagement Scale, apresentando-se média e desvio padrão para cada dimensão da UWES. O cálculo do vigor corresponde à média aritmética das respostas às questões $1,4,8,12,15$ e 17 da UWES; a dedicação, à média aritmética das respostas das questões 2,5,7,10 e 13; e a absorção consiste na média aritmética das respostas das questões 3,6 , $9,11,14$ e 16 . O escore geral corresponde à média aritmética das respostas de todas as questões da escala ${ }^{14}$.

Após o cálculo dos escores foi realizada a interpretação dos valores obtidos, conforme decodificação do Manual Preliminar UWES, sendo: 0 a $0,99=$ Muito Baixo; 1 a 1,99= Baixo; 2 a 3,99= Médio; 4 a $4,99=$ Alto; 5 a $6=$ Muito Alto ${ }^{14}$.

$\mathrm{O}$ indicador de consistência interna Alpha de Cronbach foi utilizado para verificar a confiabilidade das medidas dos construtos. Para verificar diferença entre os escores médios das dimensões da UWES e as características sociodemográficas e profissionais dos policiais militares, utilizou-se teste t para duas médias e ANOVA para três ou mais médias.

Por fim, realizou-se análise de correlação entre estresse ocupacional e as dimensões da UWES (Dedicação, Absorção, Vigor e Escore geral), utilizando-se o teste de correlação de Pearson (r) e considerando correlação fraca para valores de $r$ até 0,30 , moderada para valores entre 0,40 e 0,60 , e forte para valores maiores que 0,70 . Para todos os cálculos adotou-se nível de significância de $95 \%(\mathrm{p} \leq 0,05)$.

O estudo foi aprovado pelo Comitê de Ética em Pesquisa.

Os autores declaram não haver conflitos de interesses e que o trabalho não foi subvencionado.

\section{Resultados}

Participaram 268 policiais militares, sendo $84,7 \%$ homens, faixa etária de 31 a $40 \operatorname{anos}(46,6 \%)$, com ensino superior incompleto $(45,1 \%)$ e casados $(67,6 \%)$. A maioria era soldado $(82,8 \%)$, exercia funções operacionais $(70,1 \%)$ e trabalhava em turnos de escalas $(72,4 \%)$, sendo que $51,1 \%$ faziam escalas de $24 \times 48$ horas. Em relação ao tempo de atuação na polícia, $54,5 \%$ policiais atuavam entre três e dez anos. 90,6\% não exerciam outra atividade remunerada, $25,5 \%$ não praticavam atividade física, $48,5 \%$ já havia cometido transgressão disciplinar e $33,6 \%$ referiu a existência de problemas que comprometem a qualidade de vida (Tabela 1).

Os policiais apresentaram níveis importantes de estresse ocupacional (46,7\%), sendo $86,4 \%$ do sexo masculino, $46,4 \%$ entre 31 e 40 anos, $39,2 \%$ com ensino superior incompleto, $66,4 \%$ casados, $83,9 \%$ soldados, $71,2 \%$ exerciam funções 
Tabela 1. Características sociodemográficas e profissionais dos policiais do 3 Batalhão de Polícia Militar do estado do Paraná, Brasil, 2018.

\begin{tabular}{|c|c|c|c|}
\hline Variáveis & Categorias & $\mathbf{n}$ & $\%$ \\
\hline \multirow[t]{2}{*}{ Sexo } & Masculino & 227 & 84,7 \\
\hline & Feminino & 41 & 15,3 \\
\hline \multirow{3}{*}{$\begin{array}{l}\text { Faixa Etária } \\
\text { (anos) }\end{array}$} & $21-30$ & 111 & 41,4 \\
\hline & $31-40$ & 125 & 46,6 \\
\hline & $41-50$ & 32 & 11,9 \\
\hline \multirow[t]{4}{*}{ Escolaridade } & Ensino Médio & 73 & 27,2 \\
\hline & Ensino Superior Incompleto & 121 & 45,1 \\
\hline & Ensino Superior Completo & 71 & 26,5 \\
\hline & Não respondeu & 3 & 1,1 \\
\hline \multirow[t]{4}{*}{ Estado Civil } & Casado & 181 & 67,6 \\
\hline & Solteiro & 70 & 26,1 \\
\hline & Separado & 14 & 5,2 \\
\hline & Viúvo & 3 & 1,1 \\
\hline \multirow[t]{8}{*}{ Cargo } & Soldado & 221 & 82,8 \\
\hline & Cabo & 15 & 5,6 \\
\hline & Sargento & 13 & 4,9 \\
\hline & Subtenente & 2 & 0,7 \\
\hline & Aspirante & 5 & 1,9 \\
\hline & Tenente & 7 & 2,6 \\
\hline & Capitão & 3 & 1,1 \\
\hline & Major & 1 & 0,4 \\
\hline \multirow[t]{2}{*}{ Função } & Administrativo & 80 & 29,9 \\
\hline & Operacional & 188 & 70,1 \\
\hline \multirow{5}{*}{$\begin{array}{l}\text { Jornada de } \\
\text { Trabalho }\end{array}$} & Seis horas & 8 & 3,0 \\
\hline & Oito horas & 80 & 29,9 \\
\hline & $24 \times 48$ horas & 137 & 51,1 \\
\hline & Outros $^{*}$ & 42 & 15,7 \\
\hline & Não respondeu & 1 & 0,4 \\
\hline \multirow{4}{*}{$\begin{array}{l}\text { Turno de } \\
\text { Trabalho }\end{array}$} & Manhã e Tarde & 62 & 23,1 \\
\hline & Tarde e Noite & 11 & 4,1 \\
\hline & Escalas $^{* *}$ & 194 & 72,4 \\
\hline & Não respondeu & 1 & 0,4 \\
\hline \multirow{4}{*}{$\begin{array}{l}\text { Tempo de } \\
\text { Atuação } \\
\text { (anos) }\end{array}$} & Até três & 59 & 22,0 \\
\hline & Três a 10 & 146 & 54,5 \\
\hline & 10 a 20 & 33 & 12,3 \\
\hline & Mais de 20 & 30 & 11,2 \\
\hline Outra & Sim & 25 & 9,4 \\
\hline \multicolumn{4}{|c|}{ Remunerada } \\
\hline Atividade & $\operatorname{Sim}$ & 199 & 74,5 \\
\hline Física & Não & 68 & 25,5 \\
\hline Transgressão & Sim & 130 & 48,5 \\
\hline Disciplinar & Não & 138 & 51,5 \\
\hline Problema que & Sim & 90 & 33,6 \\
\hline Comprometa & Não & 176 & 65,7 \\
\hline QV & Não respondeu & 2 & 0,7 \\
\hline
\end{tabular}

* Jornada de trabalho de $12 \times 24$ ou $12 \times 48$ horas. ${ }^{* *}$ Turno de trabalho: $12 \times 24-12 \times 48$ ou $24 \times 48$ horas.

Fonte: Elaborado pelos autores. operacionais, $74,4 \%$ trabalhavam em turno de escalas, $49,6 \%$ em jornadas de $12 \times 24$ ou $12 \times 48$ horas, 55,2\% atuavam na PM entre três e 10 anos, $89,6 \%$ não tinham outra atividade remunerada, $5,2 \%$ praticavam atividade física e $53,6 \%$ já cometeram transgressão disciplinar (Tabela 1).

Na Tabela 2 observa-se que os aspectos estressores, segundo a percepção dos policiais militares foram: [Q16] falta de perspectivas de crescimento na carreira $(3,7 ; \pm 1,3)$; [Q13] deficiência nos treinamentos profissionais $(3,4 ; \pm 1,2)$; [Q12] presença de discriminação/favoritismo no ambiente de trabalho $(3,1 ; \pm 1,4)$; [Q10] longas jornadas de trabalho $(3,0 ; \pm 1,4)$; [Q1] forma de distribuição das tarefas $(2,7 ; \pm 1,1)$; [Q2] tipo de controle $(2,7 ; \pm 1,1)$; [Q5] deficiência na divulgação de informações sobre decisões organizacionais $(2,7 ; \pm 1,2)$; [Q15] baixa valorização por superiores $(2,7 ; \pm 1,2)$; [Q3] falta de autonomia na execução do trabalho $(2,6 ; \pm 1,1)$.

Os níveis de engajamento no trabalhovariaram de 3,8 [médio] a 4,1 [alto]. Os valores do Coeficiente Alfa de Cronbach variaram de 0,790 a 0,940 , apontando confiabilidade dos resultados, conforme mostra a Tabela 3.

Não houve diferenças estatisticamente significativas entre os escores médios das dimensões da UWES e as variáveis sociodemográficas e profissionais dos policiais militares.

A correlação entre engajamento no trabalho e estresse ocupacional foi negativa e estatisticamente significante, pois o aumento do estresse ocupacional diminui os níveis de engajamento no trabalho (Tabela 4). Observou-se correlação fraca entre estresse ocupacional e as dimensões Absorção (r:-0,284; $p<0,001)$ e Escore geral ( $r$ :$0,393 ; \mathrm{p}<0,001)$ e moderada com as dimensões Vigor (r:-0,422; $\mathrm{p}<0,001)$ e Dedicação (r:-0,414; $\mathrm{p}<0,001)$.

\section{Discussão}

Os policiais militares do $3^{\circ} \mathrm{BPM} / \mathrm{PR}$ apresentam perfil sociodemográfico e profissional semelhante ao relatado por outros estudos com policiais brasileiros ${ }^{10,15}$. O predomínio do trabalho em escalas é comum entre os policiais e corrobora a literatura $^{10,16-17}$.

A intensa e arriscada atividade do policial militar atrelada às longas jornadas de trabalho em escalas, proporciona uma predisposição natural a dores corporais, como lombalgias, devido ao longo tempo de permanência na posição ereta, uso de equipamentos, como colete balístico e cin- 
Tabela 2. Avaliação dos itens da EET, segundo a percepção dos policiais do 3o Batalhão de Polícia Militar do estado do Paraná, Brasil, 2018.

\begin{tabular}{|c|c|}
\hline Itens da EET & $\begin{array}{l}\text { Média } \\
( \pm d p)\end{array}$ \\
\hline Q1 - A forma como as tarefas são distribuídas em minha área tem me deixado nervoso & $2,7( \pm 1,1)$ \\
\hline Q2 - O tipo de controle existente em meu trabalho me irrita & $2,7( \pm 1,1)$ \\
\hline Q3 - A falta de autonomia na execução do meu trabalho tem sido desgastante & $2,6( \pm 1,1)$ \\
\hline $\begin{array}{l}\text { Q4 - Tenho me sentido incomodado com a falta de confiança de meu superior sobre o meu } \\
\text { trabalho }\end{array}$ & $2,2( \pm 1,2)$ \\
\hline $\begin{array}{l}\text { Q5 - Sinto-me irritado com a deficiência na divulgação de informações sobre decisões } \\
\text { organizacionais }\end{array}$ & $2,7( \pm 1,2)$ \\
\hline Q6 - Sinto-me incomodado com a falta de informações sobre minhas tarefas no trabalho & $2,4( \pm 1,1)$ \\
\hline Q7 - A falta de comunicação entre mim e meus colegas de trabalho deixa-me irritado & $2,1( \pm 1,0)$ \\
\hline Q8 - Sinto-me incomodado por meu superior tratar-me mal na frente de colegas de trabalho & $2,3( \pm 1,4)$ \\
\hline Q9 - Sinto-me incomodado por ter que realizar tarefas que estão além de minha capacidade & $2,4( \pm 1,2)$ \\
\hline Q10 - Fico de mau humor por ter que trabalhar durante muitas horas seguidas & $3,0( \pm 1,4)$ \\
\hline Q11 - Sinto-me incomodado com a comunicação existente entre mim e meu superior & $2,3( \pm 1,2)$ \\
\hline Q12 - Fico irritado com discriminação/favoritismo no meu ambiente de trabalho & $3,1( \pm 1,4)$ \\
\hline $\begin{array}{l}\text { Q13 - Tenho me sentido incomodado com a deficiência nos treinamentos para capacitação } \\
\text { profissional }\end{array}$ & $3,4( \pm 1,2)$ \\
\hline Q14 - Fico de mau humor por me sentir isolado na organização & $2,1( \pm 1,1)$ \\
\hline Q15 - Fico irritado por ser pouco valorizado por meus superiores & $2,7( \pm 1,2)$ \\
\hline Q16 - As poucas perspectivas de crescimento na carreira têm me deixado angustiado & $3,7( \pm 1,3)$ \\
\hline Q17 - Tenho me sentido incomodado por trabalhar em tarefas abaixo do meu nível de habilidade & $2,4( \pm 1,2)$ \\
\hline Q18 - A competição no meu ambiente de trabalho tem me deixado de mau humor & $2,0( \pm 1,0)$ \\
\hline $\begin{array}{l}\text { Q19 - A falta de compreensão sobre quais são minhas responsabilidades neste trabalho tem } \\
\text { causado irritação }\end{array}$ & $2,3( \pm 1,1)$ \\
\hline Q20 - Tenho estado nervoso por meu superior me dar ordens contraditórias & $2,2( \pm 1,1)$ \\
\hline $\begin{array}{l}\text { Q21 - Sinto-me irritado por meu superior encobrir meu trabalho bem feito diante de outras } \\
\text { pessoas }\end{array}$ & $2,2( \pm 1,1)$ \\
\hline Q22 - O tempo insuficiente para realizar meu volume de trabalho deixa-me nervoso & $2,2( \pm 1,1)$ \\
\hline Q23 - Fico incomodado por meu superior evitar me incumbir de responsabilidades importantes & $2,1( \pm 1,0)$ \\
\hline
\end{tabular}

Fonte: Elaborado pelos autores.

Tabela 3. Níveis de engajamento no trabalho dos policiais do 3 Batalhão de Polícia Militar do estado do Paraná, Brasil, 2018.

\begin{tabular}{lccccrc}
\hline \multicolumn{1}{c}{ Dimensões UWES } & $\begin{array}{c}\text { Alfa de } \\
\text { Cronbach }\end{array}$ & Md & Média \pm dp & IC (95\%) & Interpretação & p-valor* \\
\hline Vigor & 0,877 & 4,0 & $3,8 \pm 1,2$ & $3,6-3,9$ & Médio & $<0,001$ \\
Dedicação & 0,893 & 4,0 & $4,1 \pm 1,3$ & $3,9-4,2$ & Alto & \\
Absorção & 0,790 & 3,0 & $3,3 \pm 1,2$ & $3,2-3,5$ & Médio & \\
Escore Geral & 0,940 & 4,0 & $3,7 \pm 1,2$ & $3,6-3,8$ & Médio & \\
\hline
\end{tabular}

Min: mínimo, Max: máximo, Md: mediana, dp: desvio padrão, IC 95\%: intervalo de confiança de $95 \%$. ${ }^{\star}$ Test t.

Fonte: Elaborado pelos autores.

to de guarnição, e ao estresse físico e emocional. Nesse sentido, as excessivas jornadas de trabalho podem intensificar o quadro de estresse e levar ao desenvolvimento de problemas de saúde que se cronificam e comprometem a qualidade de vida destes profissionais ${ }^{10,16-18}$. 
Tabela 4. Correlações entre engajamento no trabalho e estresse ocupacional dos policiais do 30 Batalhão de Polícia Militar do estado do Paraná, Brasil, 2018.

\begin{tabular}{lcc}
\hline \multicolumn{1}{c}{ Categorias } & $\begin{array}{c}\text { Estresse } \\
\text { Ocupacional }\end{array}$ & Valor-p \\
\hline Vigor & $-0,422^{*}$ & $<0,001$ \\
Dedicação & $-0,414^{* *}$ & $<0,001$ \\
Absorção & $-0,284^{* *}$ & $<0,001$ \\
Escore geral & $-0,393^{* *}$ & $<0,001$ \\
${ }^{*}$ Correlação significativa no nível $99 \%(\mathrm{p}<0,01)$.
\end{tabular}

Fonte: Elaborado pelos autores.

O percentual de policiais militares com níveis importantes de estresse ocupacional é consoante a outros estudos e, possivelmente, consequência do ambiente laboral cercado de conflitos, que levam à exposição física e mental do policial, diante das mais diversas ocorrências. Durante a jornada de trabalho, é comum que o policial se depare com riscos iminentes, que contribuem para o surgimento do estresse, impactando na saúde do militar, como: jornada de trabalho excessiva, baixa remuneração, apoio logístico precário e falta de motivação. Nesse contexto, o processo de trabalho do policial militar pode desencadear sentimento de frustração, insegurança, conflitos e insatisfação, fatores relacionados diretamente ao estresse ocupacional ${ }^{19-20}$.

Nesse interim, as consequências do estresse ocupacional atingem níveis individual, grupal e organizacional. No individual, há queda da eficiência, sobrecarga voluntária de trabalho, explosão emocional, grande nível de tensão, sentimento de frustração, sentimentos de onipotência e agravamento de doenças. No nível grupal, surgem comportamentos hostis, discussões inúteis, pouca contribuição no trabalho, não compartilhamento de problemas e alto nível de insegurança. Já no nível organizacional ocorrem prejuízos como atrasos constantes no cumprimento de prazos, absenteísmo, alta rotatividade de funcionários, baixo nível de esforço e vínculos empobrecidos ${ }^{19,21}$.

O predomínio de estresse ocupacional entre soldados, que exerciam a função operacional evidencia que a natureza das demandas de serviços operacionais é mais intensa e desgastante, sobretudo para os profissionais de baixa patente. A literatura aponta que os policiais que atuam em funções administrativas cumprem escalas de serviços diurnos e, esporadicamente, cumprem escalas extras. Já os policiais que atuam no ser- viço operacional cumprem funções externas, atuam diretamente com a sociedade, em funções de ostensividade e na manutenção da ordem pública, onde há exposição física e mental elevada. Os riscos inerentes à atuação operacional dos policiais se materializam, sobretudo, nos confrontos armados, em que há elevada exposição e eventos fatais podem acontecer ${ }^{10,22-23}$.

O fato de mais da metade dos policiais com três a dez anos de atuação na corporação apresentarem níveis importantes de estresse ocupacional pode estar associado ao elevado rigor imposto na formação e conduta militar. A literatura sustenta que o policial militar deve cumprir com seu dever, denotando um comportamento moral e profissional irrepreensíveis, além de manter uma vida social, fora do regimento disciplinar, com comportamento ilibado ${ }^{23}$.

Da mesma forma, a pressão pelo cumprimento dos valores e dos deveres éticos dos militares, cuja insubordinação configura crime, sujeito a punições severas, é fator que gera desgaste e estresse nos policiais e pode explicar a relação do alto percentual de profissionais que já responderam por transgressões disciplinares com estresse ocupacional ${ }^{30}$.

A percepção dos policiais militares quanto à falta de perspectivas de crescimento na carreira como fator desencadeante de estresse ocupacional é corroborada por uma pesquisa geral sobre o trabalho policial no Brasil, que demonstrou que a carreira policial não tem tantos atrativos, devido à falta de perspectiva de crescimento dentro das corporações, além da perda de identidade da carreira, riscos de morte, sensação de exploração e abandono pela instituição. Tais significados assumiram referenciais negativos e associados a noções de mal-estar no trabalho, que podem favorecer o estresse ocupacional ${ }^{23}$.

Outro aspecto estressor referido foi a deficiência na qualificação profissional, cuja implementação é imprescindível para a atuação policial. Para ter ciência do momento exato de entrar em ação e garantir a segurança da sociedade, é necessário que os policiais militares sejam constantemente qualificados, a fim de garantir excelência na atuação profissional, sobretudo para que os direitos individuais e coletivos possam ser respeitados ${ }^{24}$.

Os problemas de discriminação e favoritismo no ambiente de trabalho estão associados ao comportamento antissocial dos indivíduos nas organizações, com o escopo de prejudicar os colegas e a própria instituição. $\mathrm{O}$ que ratifica tal aspecto ser considerado estressor pelos policiais 
militares, indicando a necessidade de se intervir nessa situação $0^{21}$.

Outro aspecto apontado como estressante foram as longas jornadas de trabalho a que os policiais militares são submetidos. $\mathrm{O}$ trabalho por turnos pode afetar a qualidade do sono e sua privação pode acarretar danos à saúde dos profissionais. Portanto, longas jornadas e trabalho por turnos trazem complicações no ciclo biológico e circadiano. Além disso, o alto nível de atenção e alerta exigido do policial, especialmente durante o trabalho noturno ou em longas jornadas, acrescem as chances de acidentes automobilísticos provocados por acompanhamentos táticos em ambientes sem luminosidade e confronto armado, que podem ceifar vidas ${ }^{25-26}$.

Com relação à forma de distribuição das tarefas, apontada como fator estressor importante, ressalta-se que muitas destas causam tensão e contradições na labuta policial, gerando desmotivação para prosseguir na carreira, em decorrência de intervenções que não representam a função pública da polícia e, muitas vezes, servem apenas para atender interesses particulares de superiores hierárquicos ${ }^{23}$. Essa compreensão contempla outro aspecto estressor apontado pelos policiais paranaenses, que é o tipo de controle existente em seu trabalho, pois o excessivo controle no desempenho das funções leva a alienação e, consequente irritabilidade e acentua o estresse ocupacional ${ }^{27}$.

A deficiência na divulgação das informações relacionadas às decisões organizacionais é um fator que gera irritabilidade nos policiais, evidenciando que o problema de comunicação se faz presente entre os profissionais estudados e a corporação. A comunicação interna nas instituições é um importante elemento para a gestão do conhecimento nas organizações, sobretudo de forma estratégica, visto que, quando existe boa comunicação, o ambiente corporativo torna-se melhor e gera reflexos positivos no ambiente externo ${ }^{28}$.

Além disso, a baixa valorização por superiores relacionada à falta de divulgação das informações, sobretudo decisões organizacionais, implica diretamente no cotidiano de trabalho, gerando estresse e desgaste profissional ${ }^{29}$.

Embora seja rotina dos policiais militares lidar com essas relações assimétricas de poder, o modelo rígido de patentes torna-se prejudicial na medida em que contribui para a humilhação e a desvalorização do profissional, como o uso da patente para constranger e oprimir subordinados, fato que fortalece estados de baixa autoestima e desvalorização profissional ${ }^{30}$.
Contrapondo os aspectos estressores analisados, a relação positiva dos policiais militares com o trabalho (engajamento no trabalho) foi muito boa, demonstrando que estes profissionais apresentam altos níveis de energia e se identificam com o trabalho. Os resultados observados corroboram estudos nacionais realizados com outros profissionais, como enfermeiros e trabalhadores da Atenção Primária à Saúde, residentes multiprofissionais em saúde, profissionais da saúde matriculados em programas de aprimoramento e aperfeiçoamento profissional ${ }^{31-36}$.

As variações entre valores médios e altos nos níveis de engajamento no trabalho dos policiais militares reforça que este é um fenômeno relacionado ao ambiente laboral do trabalhador, influenciado por características individuais, organizacionais e específicas do trabalho ${ }^{34}$.

O nível médio de Vigor apresentado pelos policiais pode colaborar para a redução do estresse ocupacional. Estudo recente com policiais militares apontou potencial de impacto positivo da resiliência na redução do estresse ocupacional, especialmente profissionais do sexo feminino ${ }^{37}$.

O alto nível de Dedicação evidencia que os policiais militares se encontram entusiasmados $\mathrm{e}$ identificam-se com o trabalho. De acordo com a literatura, para que os trabalhadores apresentem níveis elevados de engajamento no trabalho, é importante que o ambiente de trabalho proporcione suporte social entre os profissionais. Da mesma forma, níveis satisfatórios de Dedicação entre os trabalhadores dependerá da capacidade de suporte das chefias ${ }^{35,38}$.

Estudo sobre engajamento no trabalho e Burnout realizado nos países baixos, com mais de dois mil policiais concluiu que os profissionais que faziam parte de equipes altamente envolvidas com as atividades laborais apresentavam níveis mais elevados de Vigor, Dedicação e Absorção. Estes resultados reforçam as vantagens de ambientes laborais saudáveis para o bom desempenho das funções ${ }^{39}$.

O nível médio de Absorção retrata bom foco e concentração dos policiais na execução de suas missões, algo importante para o trabalho diário destes profissionais. Estudo realizado na Bahia demonstrou que os policiais apresentaram maiores níveis de Dedicação e Absorção do que outros profissionais. Para os autores, essa diferença pode ser maior quando se compara policiais com profissionais da saúde, assistentes sociais e conselheiros tutelares ${ }^{40}$.

No entanto, mesmo apresentando altos níveis de engajamento no trabalho, os policias podem 
apresentar cansaço físico após o expediente. Isso ocorre porque o engajamento está associado à satisfação e ao prazer na realização das funções laborais, pois mesmo cansado fisicamente, o policial encontra significado e prazer em suas atribuições, que lhe garantem os altos níveis de engajamento ${ }^{39-40}$.

Nesse contexto, para evitar que o estresse ocupacional impacte negativamente nos níveis de engajamento no trabalho dos policiais e comprometa o andamento do serviço de segurança, é importante que as corporações estimulem a relação positiva dos policiais com o trabalho, a partir da valorização e recompensa dos profissionais, adequação das cargas horárias de trabalho, flexibilização dos tipos de controle, implementação de qualificações permanentes e o reconhecimento organizacional ${ }^{41}$.

Todavia, entende-se que a concretização dessas ações representa um desafio para a saúde do trabalhador, no mundo contemporâneo e o alcance de impactos relevantes para a saúde dos policiais exige seu envolvimento, por meio de das organizações representativas, ampliando o poder de ação individual e coletivo nas negociações com superiores hierárquicos e os governos estaduais $^{42-43}$.

\section{Conclusão}

O estudo permitiu a identificação dos fatores que desencadeiam estresse ocupacional nos policiais militares e, ao identificar os níveis de engajamen- to no trabalho, favoreceu o conhecimento sobre a relação desses profissionais com o ambiente laboral.

Apesar do importante número de policiais com estresse ocupacional, estes apresentaram bons níveis de engajamento no trabalho, especialmente no domínio Dedicação, pois são altamente entusiasmados, inspirados e orgulhosos com o trabalho.

Evidenciou-se, portanto, a relevância de identificar e intervir nos fatores desencadeantes de estresse ocupacional, implementando medidas que minimizem o sofrimento e o desgaste emocional, e estimulem o engajamento no trabalho nos policiais.

Logo, este estudo contribui para o processo de implementação de estratégias que estimulem aspectos positivos e reduzam fatores negativos do trabalho policial, a partir de intervenções organizacionais que favoreçam a melhoria da saúde, da satisfação, do bem-estar e da qualidade de vida dos policiais, impactando positivamente na segurança da comunidade adscrita.

A abordagem de apenas um Batalhão da Polícia Militar representa uma limitação, por não permitir a generalização dos resultados para toda a corporação estadual ou para outras regiões do Brasil. Dessa forma, sugere-se a realização de novos estudos, com ampliação da amostra, para assegurar comparações e discussão de semelhanças e diferenças regionais, permitindo a ampliação do conhecimento sobre essa temática relevante, no âmbito da promoção da Saúde do Trabalhador na sociedade contemporânea.

\section{Colaboradores}

FB Santos, LG Lourenção e E Vieira contribuíram para a concepção e elaboração do projeto, aquisição, análise e interpretação dos dados, redação e aprovação final do artigo. FRG Ximenes Neto, AMN Oliveira, JF Oliveira, MA Borges e TR Arroyo, contribuíram para a redação e aprovação final do artigo. 


\section{Referências}

1. Van Gelderen B, Bik LW. Affective organizational commitment, work engagement and service performance among police officers. Policing: An Intern J 2015; 39(1):206-221.

2. Pires LAA, Vasconcellos LCF, Bonfatti RJ. Military firefighters of Rio de Janeiro: na analysis of the impacts of their activities on their health. Saude Debate 2017; 41(113):577-590.

3. Godinho MR, Ferreira AP, Fayer VA, Bonfatti RJ, Greco RM. Capacidade para o trabalho e fatores associados em profissionais no Brasil. Rev Bras Med Trab 2017; 15(1):88-100.

4. Eberhardt LD, Carvalho M, Murofuse NT. Vínculos de trabalho no setor saúde: o cenário da precarização na macrorregião Oeste do Paraná. Saude Debate 2015; 39(104):18-29.

5. Mata NT, Pires LAA, Bonfatti RJ. Bombeiros militares: um olhar sobre a saúde e violência relacionados com o trabalho. Saude Debate 2017; 41(112):133-141.

6. Hu Q, Schaufeli WB, Taris TW. How are changes in exposure to job demands and job resources related to burnout and engagement? A longitudinal study among Chinese nurses and police officers. Stress Health 2017; 33(5):631-644.

7. Porto-Martins PC, Basso-Machado PG, Benevides -Pereira AMT. Engagement no trabalho: uma discussão teórica. Fractal Rev Psicol 2013; 25(3):629-644.

8. Schaufeli WB. Work engagement: What do we know and where do we go. Rom J Appl Psychol 2012; 14(1):310 .

9. Sousa I, Mendonça H, Zanini D, Nazareno E. Estresse Ocupacional, Coping e Burnout. Revista EVS - Rev Ciências Ambientais Saúde 2010; 36(1):57-74.

10. Arroyo TR, Borges MA, Lourenção LG. Health and quality of life of military police officers. Rev Bras Promoç Saude 2019; 32:7738.

11. Secretaria de Segurança Pública e Administração Penitenciária, Polícia Militar do Paraná. $5^{\circ}$ Comando Regional de Polícia Militar: $3^{\circ}$ BPM - Histórico. Curitiba; 2017. [acessado 2020 maio 23]. Disponível em: http:// www.pmpr.pr.gov.br/Pagina/Historico.

12. Paschoal TE, Tamayo A. Validação da Escala de Estresse no Trabalho. Estud Psicol 2004; 9(1):45-52.

13. Vasquez ACS, Magnan ES, Pacico JC, Hutz CS, Schaufeli WB. Adaptation and Validation of the Brazilian Version of the Utrecht Work Engagement Scale. Psico-USF 2015; 20(2):207-217.

14. Agnst R, Benevides-Pereira AMT, Porto-Martins PC. Utrecht Work Engagement Scale. Curitiba: GEPEB; 2009.

15. Almeida DM, Lopes LFD, Costa VMF, Santos RCT, Corrêa JS. Satisfação no Trabalho dos Policiais Militares do Rio Grande do Sul: um Estudo Quantitativo. Psicol Cienc Prof 2016; 36(4):801-815.

16. Brasil VP, Lourenção LG. Qualidade de vida de policiais militares do interior do estado de São Paulo. Arq Cienc Saude 2017; 24(1):81-5.

17. Knapik JJ, Graham B, Cobbs J, Thompson D, Steelman $\mathrm{R}$, Jones $\mathrm{BH}$. A prospective investigation of injury incidence and risk factors among army recruits in combat engineer training. J Occup Med Toxicol 2013; 8(1):5.
18. Neto A, Faleiro T, Moreira F, Jambeiro J, Schulz R. Lombalgia na atividade policial militar: análise da prevalência, repercussões laborativas e custo indireto. Rev Baiana Saude Publ 2013; 37(2):365-374.

19. Aguiar FLS. Estresse ocupacional: contribuições das pirâmides coloridas de Pfister no contexto policial militar [dissertação]. Belém: Universidade Federal do Pará; 2007. [acessado 2020 maio 23]. Disponível em: http:// repositorio.ufpa.br/jspui/handle/2011/1890.

20. Santos MJ, Jesus SS, Tupinambá MRP, Brito WF. Percepção de policiais militares em relação ao estresse ocupacional. Revista humanidades 2018; 7(2):42-54.

21. Almeida DM, Lopes LFD, Costa VMF, Santos RCT, Corrêa JS. Avaliação do estresse ocupacional no cotidiano de policiais militares do Rio Grande do Sul. Organizações em Contexto 2017; 13(26):215-238.

22. Bernardo VM, Silva FC, Ferreira EG, Bento GG, Zilch MC, Sousa BA, Silva R. Atividade física e qualidade de sono em policiais militares. Rev Bras Ciênc Esporte 2018; 40(2):131-137.

23. Silveira RA, Medeiros CR. O herói-envergonhado: tensões e contradições no cotidiano do trabalho policial. Rev Bras Segur Publica 2016; 10(2):134-153.

24. Venez HSC, Soares MF. A capacitação profissional continuada em tiro policial na polícia militar do tocantins. Aturá - Rev Pan-Amazônica Comunicação 2018; 2(3):284-305.

25. Bernardo VM, Cascaes SF, Gonçalves E, Soleman HSS, Valdivia ABA, Silva R. Efeitos do Trabalho em Turnos na Qualidade do Sono de Policiais: Uma Revisão Sistemática. Rev Cub Med Mil 2015; 44(3):334-345.

26. Waggoner LB, Grant DA, Van Dongen HP, Belenky G, Vila B. A combined field and laboratory design for assessing the impact of night shift work on police officer operational performance. Sleep 2012; 35(11):15751577.

27. Cruz ER, Silva MJ, Menegassi C. A comunicação interna nas organizações na perspectiva da gestão do conhecimento. In: Anais da IX Mostra Interna de Trabalhos de Iniciação Científica e II Mostra Interna de Trabalhos de Iniciação em Desenvolvimento Tecnológico e Inovação; 2018; Maringá. [acessado 2020 maio 23]. Disponível em: http://rdu.unicesumar.edu.br// handle/123456789/2299.

28. Bellenzani R, Paro DM, Oliveira MC. Trabalho em saúde mental e estresse na equipe: questões para a política nacional de humanização/SUS. Rev Psicol Saude 2016; 8(1):32-43.

29. Tabosa MPO, Cordeiro AT. Estresse ocupacional: análise do ambiente laboral de uma cooperativa de médicos de Pernambuco. ReCaPe 2018; 8(2):282-303.

30. Sales LJM, Sá LD. A condição do policial militar em atendimento clínico: uma análise das narrativas sobre adoecimento, sofrimento e medo no contexto profissional. Repocs 2016; 13(25):181-206.

31. Lourenção LG, Silva AG, Borges MA. Levels of engagement in primary health care professionals: a comparative study in two Brazilian municipalities. Esc Anna Nery 2019; 23(3):e20190005. 
32. Silva AG, Cabrera EMS, Gazetta CE, Sodre PC, Castro JR, Cordioli Junior JR, Cordioli DFC, Lourenção LG. Engagement in primary health care nurses: A crosssectional study in a Brazilian city. Public Health Nurs 2020; 37(2):169-177.

33. Cordioli DFC, Cordioli Junior JR, Gazetta CE, Silva AG, Lourenção LG. Occupational stress and engagement in primary health care workers. Rev Bras Enferm 2019; 72(6):1580-1587.

34. Lourenção LG. Work engagement among participants of residency and professional development programs in nursing. Rev Bras Enferm 2018; 71(Supl. 4):14871492.

35. Gonsalez EG, Lourenção LG, Teixeira PR, Rotta DS, Gazetta CE, Beretta D, Pinto MH.Work engagement in employees at professional improvement programs in health. Cad Bras Ter Ocup 2017; 25(3):509-517.

36. Rotta DS, Lourenção LG, Gonsalez EG, Teixeira PR, Gazetta CE, Pinto MH. Engagement of multi-professional residents in health. Rev Esc Enferm USP 2019; 530:e03437.

37. Chitra T, Karunanidhi S. The Impact of Resilience Training on Occupational Stress, Resilience, Job Satisfaction, and Psychological Well-being of Female Police Officers. J Police Crim Psych 2018; 3:1-16..

38. Sullivan HD, Warshawsky NE, Vasey J. RN work engagement in generational cohorts: The view from rural US hospitals. J Nurs Manag 2013; 21(7):927-940.

39. Bakker AB, Emmerik H van, Euwema MC. Crossover of burnout and engagement in work teams. Work and occupations 2006; 33(4):464-489.
40. Guedes HD. Trabalho emocional, identidade e engajamento no trabalho com policiais militares: Testando modelos de predição e mediação [dissertação]. Salvador: Universidade Federal da Bahia; 2018. [acessado 2020 maio 23]. Disponível em: https://repositorio. ufba.br/ri/handle/ri/25662.

41. Bakker AB, Albrecht SL, Leiter MP. Key questions regarding work engagement. Eur. J Work Organ Psychol 2011; 20(1):4-28.

42. Souza KR, Rodrigues AMS, Fernandez VS, Bonfatti RJ. A categoria saúde na perspectiva da saúde do trabalhador: ensaio sobre interações, resistências e práxis. Saude Debate 2017; 41(n. spe. 2):254-263.

43. Jackson Filho JM, Pina JA, Vilela RGA, Souza KR. Desafios para a intervenção em saúde do trabalhador. Rev Bras Saude Ocup 2018; 43(Supl. 1):e13s.

Artigo apresentado em 01/06/2020

Aprovado em 21/07/2021

Versão final apresentada em 23/07/2021

Editores-chefes: Romeu Gomes, Antônio Augusto Moura da Silva 